\title{
DEOIS FENNAH, DESCRIÇÃO DE UMA ESPÉCIE NOVA E NOTAS TAXONÔMICAS (HOMOPTERA, CERCOPIDAE, TOMASPIDINAE) ${ }^{1}$
}

\author{
Rodney R. Cavichioli ${ }^{2}$ \\ Albino M. Sakakibara ${ }^{2}$
}

\begin{abstract}
DEOIS FENNAH, DESCRIPTION OF A NEW SPECIES AND TAXONOMIC NOTES (HOMOPTERA, CERCOPIDAE, TOMASPIDINAE). Deois mourei, sp.n. (= Deois picklesi; Sakakibara, 1979) is described from Curitiba, Paraná, Brazil. Menecphora coerulea Lallemand, 1924 is transferred to Deois Fennah, 1948.

KEY WORDS. Homoptera, Cercopidae, Tomaspidinae, Deois, new species
\end{abstract}

SAKAKIBARA (1979) redescreveu Deois picklesi (China \& Myers, 1934) com base em material existente na Coleção de Entomologia Pe. Jesus Santiago Moure, Departamento de Zoologia, Universidade Federal do Paraná. Recentemente, foi possível examinar-se o holótipo da espécie, depositado no The Natural History Museum, Londres e verificou-se que aquela tratada por SAKAKIBARA, embora muito parecida, fosse uma espécie ainda não descrita.

Examinou-se também, o holótipo de Monecphora coerulea Lallemand, 1924, o que permitiu a sua transferência para o gênero Deois.

\section{Deois mourei, sp.n.}

Deois picklesi: Sakakibara, 1979:13, figs 6-10.

Holótipo macho. Curitiba, Paraná; Brasil, 16-II-1966; C. Ext. DZUFPleg. Depositado na Coleção de Entomologia Pe. Jesus Santiago Moure, Departamento de Zoologia, Universidade Federal do Paraná (DZUP). Alótipo fêmea, com os mesmos dados do holótipo.

Parátipos. Brasil: Minas Gerais, Campo Belo, Fazenda Boa Vista, 08-XI-1976, Melo L.A.S. leg., um macho; São Paulo, Barueri, XI-1957, K. Lenko leg., um macho; Mato Grosso do Sul, Campo Grande, Koller leg., um macho e dezfêmeas; Paraná, Curitiba, 15-II-1961, S. Larocaleg., um macho e sete fêmeas; 16-II-1966, C. Ext. DZUP leg., dez machos e dez fêmeas; XI-1969, P.D. Hurd leg., um macho; Estrada Curitiba-Rio Branco, 20-I-1982, A.M. Sakakibara \&

1) Contribuição número 757 do Departamento de Zoologia, Universidade Federal do Paraná.

2) Departamento de Zoologia, Universidade Federal do Paraná, Caixa Postal 19020, 81531-970 Curitiba, Paraná, Brasil. 
R.R. Cavichiolileg., uma fêmea; Ponta Grossa, III-1944, Justus leg., duas fêmeas; Santa Catarina, Caçador, II-1984, A.I. Orth leg., dois machos e uma fêmea; Rio Grande do Sul, Porto Alegre, 1975, M. Becker leg., duas fêmeas. Depositados na mesma Coleção do holótipo.

Medidas em milímetros.
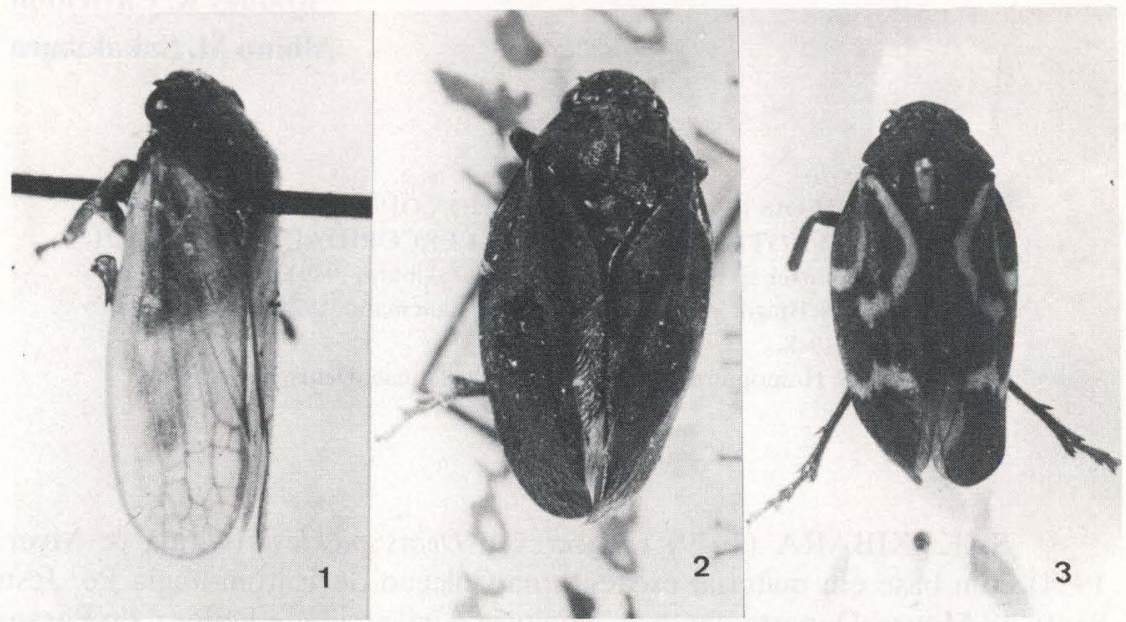

Figs 1-3. Vista dorsal. (1) Deois picklensis, holótipo; (2) Deois coerulea, holótipo; (3) Deois flexuosa, holótipo.

Holótipo Macho/Alótipo fêmea. Comprimento total: 8,17/9,00; comprimento mediano da cabeça: $0,56 / 0,72$; largura transocular: 1,88/2,12; largura interocular: 1,12/1,20; comprimento mediano do pronoto: 1,60/1,92; largura máxima do pronoto: 2,40/2,80; comprimento da tégmina: 6,52/7,00; largura máxima da tégmina: 2,20/2,40.

Comprimento dos machos: 7,20-9,00; média: 7,77.

Comprimento das fêmeas: 8,30-9,58; média: 9,04.

Caracteres diagnósticos. Coloração geral marrom-clara, mais escura na cabeça e pronoto; tégminas com uma faixa cortando o clavo desde a base até o ápice e uma outra pouco distinta, junto à margem costal no terço basal, amarelopálidas; tórax, abdômen e pernas, marrom-claro. Edeago simples, curvo, com a porção à frente do forâmen em forma de canaleta e com diversos dentículos na parte dorsal.

Descrição. Cabeça em vista dorsal, subtriangular, aproximadamente três vezes mais larga do que longa, pilosidade densa, decumbente e semelhante à do pronoto. Vértice levemente elevado na região ocular e com uma leve carena longitudinal mediana no tilo; ocelos proeminentes, situados atrás da linha imaginária que tangencia os bordos anteriores dos olhos e mais próximos da margem posterior; olhos proeminentes e transversos. Lóbulos suprantenais, em vista dorsal, levemente salientes, em vista lateral, carenados e transversos; 
antenas conspícuas, com escapo curto e cilíndrico; pedicelo de comprimento aproximadamente igual a duas vezes o seu diâmetro basal, cilíndrico; flagelo com o corpo pequeno, ovóide, e estilo alongado; arista implantada no mesmo plano do estilo, com comprimento aproximadamente igual ao do pedicelo. Clípeo ovóide, inflado, com impressões musculares nítidas e com uma carena mediana evidente e contínua àquela do tilo, pilosidade densa, de perfil arredondado e limite com o anteclípeo distinto. Anteclípeo, em vista ventral, triangular, não intumescido, com margem anterior arredondada, piloso. Rostro com artículo apical mais curto que o precedente, atingindo a margem posterior das coxas mesotorácicas.

Pronoto hexagonal, com comprimento mediano dois terços da largura entre os úmeros, convexo, superfície dorsal densamente pontuada e pouco pilosa, margem anterior levemente arqueada, as látero-anteriores retas e convergentes anteriormente; margens látero-posteriores levemente emarginadas e a posterior com uma forte reentrância mediana. Escutelo triangular, quase tão largo basalmente quanto longo, sem esculturações e densamente piloso. Tégminas três vezes mais longas do que largas, ápice parabólico, venação distinta e reticulada no terço apical; com pontuações finas e pilosidade densa. Asas hialinas, levemente corrugadas, pilosidade densa, venação distinta, lóbulo hamulífero triangular, com três hâmulos; veia cúbito levemente engrossada na base.

Pernas normais; fêmures posteriores com um espinho apical, tíbias posteriores com dois espinhos, o basal mais curto; ápice das tíbias posteriores com 13 espinhos em duas fileiras e em arranjo irregular. Tarsos posteriores densamente pilosos, com tarsômero basal de comprimento igual à soma dos dois distais e com uma fileira de 14 espinhos no ápice.

Pigóforo curto, com duas projeções triangulares na margem posterior, sendo a dorsal menor, com microcerdas ao longo da margem posterior. Placa subgenital bipartida, côncava, curva para cima; margem apical emarginada formando dois lobos divergentes, o externo bem maior. Parâmeros robustos, distalmente afilados e margem externa, em vista dorsal, serrilhada; o dente apical saliente, unciforme, com ápice voltado para a região caudal. Edeago simples, curvo e com a porção à frente do forâmen em forma de canaleta e com diversos dentículos na parte dorsal.

Fêmea. Semelhante ao macho, levemente maior. Processos basais do ovopositor obsoletos, quase inexistentes.

Discussão. Espécie muito parecida com Deois picklesi (China \& Myers, 1934) (Fig. 1), tanto no aspecto geral como também nas estruturas da genitália; um pouco maior (D. picklesi atinge apenas $7,2 \mathrm{~mm}$ de comprimento) e as faixas esbranquiçadas do clavo e da margem costal das tégminas bem evidentes. $D$. picklesi tem distribuição geográfica restrita ao norte do Brasil, ao passo que $D$. mourei, sp.n. tem ocorrência maior no sul (de Minas Gerais ao Rio Grande so Sul). 


\section{Deois coerulea (Lallemand, 1924), comb.n.}

Fig. 2

Monecphora coerulea Lallemand, 1924: 383; holótipo no The Natural History Museum, Londres, proveniente de São Paulo.

O exame do holótipo (Fig. 2), permitiu transferi-la para o gênero Deois Fennah. É uma espécie muito parecida com D. flexuosa (Walker, 1851) (Fig. 3) da qual examinou-se o holótipo; tem o mesmo tamanho e também o colorido geral de fundo castanho-escuro, quese preto, com reflexos metálicos; as estruturas da genitália são semelhantes. Difere de $D$. flexuosa, principalmente pelo colorido geral uniforme, sem qualquer desenho nas tégminas. Pelo material que se dispõem, a sua distribuição geográfica está restrita à faixa litorânea na Mata Atlântica, entre o Espírito Santo e Paraná.

AGRADECIMENTOS. A M.D. Webb, do The Natural History Museum, que sempre atendeu às nossas solicitações.

\section{REFERÊNCIAS BIBLIOGRÁFICAS}

CHINA, W.E. \& J.G. MYERS. 1934. Critical notes on some Neotropical species of Tomaspis (Homoptera-Cercopidae). Ann. \& Mag. Nat. Hist. 10 (10) 29: 448-466.

FENNAH, R.G. 1948. New genera and species of Neotropical Cercopoidea (Homoptera). Ann. \& Mag. Nat. Hist. 1 (12): 605-620.

LALLEMAND, V. 1924. Homoptères nouveaux de la Collection du Muséum National de Paris e de la mienne. Bull. Mus. d'Hist. Nat. Paris: 378-385.

SAKAKIBARA, A.M. 1979. Sobre algumas espécies brasileiras de Deois Fennah, 1948 (Homoptera, Cercopidae). Revta bras. Biol. 39 (1): 9-30.

WALKER, F. 1851. List of Specimens of Homopterous Insects in the Collection of the British Museum 3: 637-907.

Recebido em 31.VIII.1993; aceito em 28.III. 1994. 